\title{
O efeito da infidelidade sobre a atratividade facial de homens e mulheres
}

\author{
Rosana Suemi Tokumaru \\ Sérgio Werner Baumel \\ Fabiane Cruz Gama Aires \\ Daniela Palaoro Viana \\ Laís de Almeida Ambrósio \\ Yara Nascimento de Aguiar \\ Rojane Neves Monteiro \\ Universidade Federal do Espírito Santo
}

\begin{abstract}
Resumo
Os estudos da atratividade e da seleção de parceiros têm recebido atenção especial dentro da perspectiva da Psicologia Evolucionista, mostrando influências tanto de fatores físicos quanto de fatores não-físicos. Neste estudo, utilizou-se de fotografias da face de homens e mulheres, pré-julgados como medianamente atraentes, desconhecidos dos participantes, associadas a uma história neutra ou que envolvia comportamento de infidelidade, para avaliar a influência de informação sobre o comportamento de infidelidade na avaliação da atratividade de indivíduos do sexo oposto. Os resultados mostraram diferenças significativas apenas quando as mulheres avaliavam fotografias de homens, atribuindo menor atratividade a homens associados à história de infidelidade. As diferenças entre homens e mulheres podem refletir mecanismos adaptativos para a avaliação da atratividade do sexo oposto relacionados às diferenças nos custos reprodutivos. Esses resultados são discutidos sob a perspectiva da Psicologia Evolucionista.
\end{abstract}

Palavras-chave: atratividade facial; infidelidade; psicologia evolucionista; diferenças sexuais.

\begin{abstract}
The effect of infidelity on male and female facial attractiveness. Studies of attractiveness and mate selection have received special attention within the Evolutionary Psychology perspective, showing influences from both physical and non-physical factors. In the present study, we used photographs showing faces of men and women, pre-judged as median attractive people, unknown to the participants, associated with neutral stories or stories involving infidelity behavior, to investigate the influence of information about infidelity behavior on the evaluation of attractiveness of opposite sex individuals. Results showed significant differences only when women evaluated men's photographs, attributing lower attractiveness to men associated with a story of infidelity. The sex differences found may represent adapted mechanisms to evaluate opposite sex attractiveness related to differences in reproductive costs. These results are discussed mainly under the Evolutionary Psychology perspective.
\end{abstract}

Keywords: facial attractiveness; infidelity; evolutionary psychology; sex differences.

$\mathrm{A}$ existência de reprodução sexuada leva, inevitavelmente, à necessidade de encontrar um parceiro, existindo diversas formas de os organismos mostrarem seu sexo e sua disponibilidade para acasalamento na natureza. Em muitos casos, o dimorfismo sexual pode servir a esse propósito, sendo encontradas situações nas quais as características físicas parecem servir apenas ao propósito de atrair parceiros do sexo oposto, como no caso, bastante citado, das caudas dos pavões (Houle \&
Kondrashov, 2002). Para os humanos, a atratividade física pode ter tanto componentes biológicos inatos, construídos ao longo da história evolutiva da espécie, quanto componentes culturais, adquiridos ao longo da vida do indivíduo (Bronstad \& Russell, 2007; Hönekopp, 2006; Lippa, 2007).

Apesar da noção popular de que a beleza depende do olhar individual, vários trabalhos mostram uma grande concordância na avaliação da atratividade entre culturas diferentes. Little, 
Apicella e Marlowe (2007), por exemplo, mostram que a simetria facial correlaciona-se positivamente com a atratividade tanto no Reino Unido quanto entre os Hazda (uma sociedade de caçadores-coletores da Tanzânia), embora essa correlação seja mais importante entre os Hazda do que entre os britânicos - possivelmente refletindo as condições ambientais diferentes, que levariam a uma maior valorização das características que apontem para melhores condições de saúde e qualidade genética numa comunidade onde as taxas de mortalidade são maiores e a expectativa de vida, menor.

Por outro lado, Hönekopp (2006) defende a ideia de que os padrões de julgamento de atratividade facial não sejam necessariamente tão universais, criticando os estudos existentes por interpretar erroneamente conceitos estatísticos, desprezando a contribuição do "gosto privado", e focalizando apenas no "gosto comum". Bronstad e Russell (2007) mostraram que pares de amigos, irmãos e casais mostram uma taxa de concordância na avaliação de atratividade facial significativamente maior que pares de estranhos da mesma raça e cultura, reforçando as evidências de que a avaliação da atratividade é organizada socialmente. Um componente dessa organização social pode ser o fator similaridade, que tem correlação com a atração, como lembram Ramos e Pasquali (1993), que encontraram correlação significativamente positiva entre atração intersexual e autoconceito de modo consistente com os achados de outras culturas, confirmando a tendência à homogamia.

A simetria e a similaridade são apenas alguns dos vários parâmetros que demonstradamente afetam a percepção de atratividade física. Outros fatores incluem uma pele sem manchas, cabelos brilhantes, ausência de deformidades físicas aparentes e traços "médios" (largura, tamanho dos olhos, da boca, etc.), considerados mais atraentes do que aqueles que desviam muito da média (Rhodes, 2006). Em relação ao corpo, embora as proporções (relação quadril-cintura) sejam destacadas como fatores determinantes de atratividade física (Schützwohl, 2006), estudos recentes mostram que a contribuição de outros fatores, incluindo o índice de massa corpórea e o índice volume-altura, podem até ser mais importantes (Fan, Dai, Qian, Chau, \& Liu, 2007; Swami \& Tovée, 2005).

Ainda outro fator freqüentemente apontado como determinante para a percepção da atratividade física facial são os caracteres sexualmente dimórficos (Penton-Voak et al., 2001; Perrett et al., 1998), de modo que as mulheres consideram mais atraentes faces masculinas que tenham características mais "másculas", como sobrancelhas grossas e uma linha mandibular acentuada, enquanto os homens preferem características "femininas" como olhos grandes e lábios grossos, características que, segundo Hönn e Göz (2007), fazem com que a face feminina pareça tanto infantil quanto madura e expressiva.

As características dimórficas podem ser sinalizadores de outros atributos "vantajosos" de homens e mulheres. Fink, Neave e Seydel (2007), estudando relações entre a força física e a atratividade de faces masculinas para mulheres, encontraram correlação significativamente positiva, apoiando a suposição de que a força física masculina pode estar sinalizada por características físicas perceptíveis na face. Roney, Hanson,
Durante e Maestripieri (2006) mostraram que mulheres consideram mais atraentes fotografias de faces dos homens que têm taxas mais elevadas de testosterona e maior interesse por crianças, sugerindo uma possível capacidade feminina para detectar, através de "dicas" nas faces masculinas, características que os tornam melhores candidatos para acasalamento. Já os aspectos considerados femininos podem estar relacionados à juventude e à capacidade reprodutiva, envolvendo taxas de estrógenos, fazendo com que faces digitalmente "feminilizadas" de mulheres sejam consideradas mais atraentes (Perrett et al., 1998). A correlação entre os hormônios sexuais, especialmente os candidatos a feromônios, e a influência do dimorfismo sexual na atratividade facial foi mostrada por Cornwell et al. (2004) que identificaram que mulheres apresentam preferência por faces mais masculinas quando próximas à ovulação, especialmente quando avaliando como candidatos a relacionamentos de curto prazo (Jones et al., 2008).

Além de a atratividade física ser o fator predominante na escolha inicial de parceiros, as pessoas tendem a associar atratividade física com outras características positivas, como se fosse verdadeiro que "o que é bonito é bom", efeito constatado por Dion, Berscheid e Walster (1972). Tal efeito foi confirmado por Omote (1991), mostrando que estudantes universitários atribuem mais características favoráveis a fotografias de crianças mais atraentes do que a fotografias de crianças menos atraentes. Este viés pode ser encontrado até mesmo entre profissionais como professores (Ross \& Salvia, 1975) e psicólogos escolares (Elovitz \& Salvia, 1982). Esse é um caso especial do "efeito halo" (Thorndike, 1920), que se refere à nossa tendência em presumir que as pessoas que tem uma característica positiva provavelmente terão outras.

Por outro lado, alguns estudos apontam, de forma bastante sugestiva, para a influência inversa, de fatores não-físicos sobre a avaliação da atratividade física. Gross e Crofton (1977), numa espécie de "resposta" ao trabalho de Dion et al. (1972), mostraram que descrições de personalidade mais favoráveis aumentavam as notas médias atribuídas à atratividade física de estudantes universitárias em fotografias.

Outros fatores também foram estudados. Um exemplo inusitado é o efeito "fim de noite" (closing time; Gladue \& Delaney, 1990), que mostra que a avaliação da atratividade de pessoas do sexo oposto melhora à medida que se aproxima a hora de encerramento das atividades em um bar, independentemente do consumo de bebidas alcoólicas. Tal efeito pode estar relacionado ao fato de que, em termos de reprodução e preservação dos genes, é mais vantajoso ser menos seletivo na escolha de um parceiro do que ficar sem parceiro algum. Jensen-Campbell, Graziano e West (1995) estudaram os efeitos da orientação prósocial e da dominância em homens sobre sua atratividade para as mulheres, encontrando um efeito significativo apenas para a orientação pró-social, que teve uma correlação positiva com a atratividade. Hill e Buss (2008) demonstraram que o julgamento da atratividade pode ser influenciado pelo contexto social no qual o individuo é apresentado. Os participantes julgaram fotografias de pessoas do sexo oposto apresentadas sozinhas, com colegas de mesmo sexo ou com colegas do sexo oposto. Os 
homens atribuíram maior atratividade para as mulheres quando apresentadas sozinhas ou com colegas do mesmo sexo enquanto as mulheres atribuíram maior atratividade aos homens quando acompanhados por colegas do sexo oposto. De acordo com os autores, para os homens a presença de outros homens junto à pessoa avaliada indica maior probabilidade de competição intra-sexual. Para as mulheres a presença de outras mulheres junto à pessoa avaliada pode indicar que ele possua algumas das características valorizadas pelas mulheres, como disponibilidade de investir em relacionamentos de longo prazo.

Kniffin e Wilson (2004) conduziram três estudos para avaliar a influência de fatores não físicos sobre a percepção da atratividade física. Esses foram denominados pelos autores de "naturalísticos", por basearem-se em situações que ocorrem naturalmente, em vez de avaliações sobre a atratividade de estranhos. Para tanto, foram avaliadas a atratividade física de pessoas conhecidas, em fotografias de anuários de escola (ensino médio) e em dois grupos orientados para tarefas específicas. Nos três estudos foram encontradas fortes influências de fatores não físicos sobre o julgamento da atratividade física. No entanto, embora ambos os sexos tenham mostrado essa influência de modo significativo, a avaliação que os homens fizeram a respeito da atratividade das mulheres foi menos influenciada pelos fatores não-físicos do que a avaliação que as mulheres fizeram sobre a atratividade dos homens. Esta diferença não ocorreu na avaliação de atratividade de pessoas do mesmo sexo, os homens tenderam a valorizar os fatores não-físicos de outros homens de modo semelhante ao que fizeram as mulheres em relação a outras mulheres.

Essas influências podem ser percebidas desde muito cedo. Lee-Manoel, Morais, Bussab e Otta (2002), examinando a possibilidade de que características não-físicas afetem o julgamento de atratividade de crianças pré-escolares (em média cinco anos de idade), mostraram ligações bem estabelecidas entre afeto, julgamento de atratividade e avaliações comportamentais nessas crianças, que tenderam a associar, em seus colegas, características positivas como ajudar mais, agredir menos, ser mais sociável e mais alegre, ao julgamento de "gostar" em geral e também considerar mais bonito.

Kniffin e Wilson (2004) resumem estes achados apontando que as decisões com que cada indivíduo se defronta, em termos de onde ir e com quem interagir, requerem a avaliação do valor adaptativo das alternativas e que essa avaliação é feita em larga escala de modo inconsciente, de modo que as alternativas mais valiosas, em termos adaptativos, são simplesmente percebidas como mais atraentes, e o indivíduo é como que "levado" ao que é considerado como mais atraente.

Os trabalhos localizados por nós testaram o efeito de determinadas características não físicas, como a familiaridade com a pessoa julgada, o gostar da pessoa julgada e o comportamento cooperativo demonstrado pela pessoa julgada, sobre o julgamento da atratividade física. Não encontramos trabalhos que tenham testado o efeito do comportamento de infidelidade da pessoa julgada sobre o julgamento de sua atratividade física. Vários autores têm demonstrado que tanto homens quanto mulheres atribuem alto valor à fidelidade do parceiro (Buss, 1989; Buss \& Barnes, 1986; Buss, Shackelford, Kirkpatrick, \& Larsen, 2001; Easton, Schipper, \& Shackelford, 2007; Miller, 2007; Minervini \& McAndrew, 2006; Rowatt, Delue, Strickhouser, \& Gonzales, 2001; Shackelford \& Buss, 1997), principalmente quando o parceiro é considerado para um relacionamento de longo prazo. Os autores citados argumentam que a valorização da fidelidade pode ser interpretada como adaptativa no sentido evolutivo, já que a infidelidade pode sinalizar desvio de recursos reprodutivos importantes. Para os homens, a infidelidade feminina pode sinalizar investimento em prole alheia enquanto para as mulheres a infidelidade masculina pode sinalizar desvio de recursos para outras mulheres e prole.

A partir dos resultados expostos, procuramos investigar a possível influência de um fator não físico específico, a infidelidade, sobre a percepção da atratividade física entre homens e mulheres. Buscamos também verificar as possíveis diferenças entre os gêneros de acordo com as previsões feitas a partir da perspectiva da Psicologia Evolucionista.

\section{Método}

\section{Participantes}

Participaram da primeira fase do estudo sessenta pessoas, trinta homens, com idades entre dezoito e trinta anos, recrutadas por conveniência em diversos locais freqüentados pelos pesquisadores, em caráter voluntário.

Duzentas e nove pessoas, cento e cinco homens, com idade entre dezoito e trinta anos, participaram da segunda fase, recrutadas entre os freqüentadores do laboratório de informática da Universidade Federal do Espírito Santo, em caráter voluntário.

\section{Instrumento}

Para a elaboração dos instrumentos desta pesquisa, foram inicialmente escolhidas por volta de cem fotografias de pessoas anônimas, no sítio Flickr (www.flickr.com), por ser um sítio com grande quantidade de fotografias sem restrição de uso (desde que não comercial) e que retrata pessoas anônimas. $\mathrm{O}$ critério para a escolha envolveu a exibição de rosto inteiro, com o olhar diretamente para a câmera, de preferência sem acessórios (como brincos, óculos, colares, maquiagem) e com expressão neutra. Das várias fotografias selecionadas foram escolhidas vinte de cada sexo, que foram consideradas pelos pesquisadores, em avaliação consensual, como sendo de atratividade mediana. A utilização de fotografias para a pesquisa de atratividade física facial tem sido validada, inclusive no Brasil (Omote, 1994), mostrando também que a percepção da atratividade física facial tem generalidade e estabilidade ao longo do tempo.

Para a primeira etapa da pesquisa foram feitos dois arquivos de apresentação de "slides", um de cada sexo, contendo cada "slide" uma das vinte fotografias, com o número correspondente da mesma no lado esquerdo da tela. Foi também elaborado um formulário de respostas para atribuição de uma "nota" de zero a dez - sendo zero o menos atraente possível e dez o mais atraente possível - para cada uma das fotografias apresentadas.

$\mathrm{Na}$ segunda fase da pesquisa utilizou-se doze das quarenta fotografias utilizadas inicialmente, seis de homens e seis de 
mulheres. Foram então criadas seis descrições que incluíam informações pessoais (nome, idade, estado civil e profissão) e uma história de infidelidade, para metade das descrições, e uma história neutra sobre o trabalho, estudo ou amizades, para a outra metade das descrições. Cada descrição foi adaptada ao sexo da pessoa fotografada (Tabela 1). As descrições continham aproximadamente o mesmo número de caracteres. Cada descrição foi atribuída de modo aleatório a uma das fotografias.

Tabela 1

Informações apresentadas junto a cada fotografia para as mulheres e para os homens dos grupos IP e IPH

\begin{tabular}{|c|c|c|}
\hline $\begin{array}{l}\text { Número da } \\
\text { fotografia }\end{array}$ & Informações apresentadas às mulheres* & Informações apresentadas aos homens* \\
\hline 1 & $\begin{array}{l}\text { Pedro Henrique, } 29 \text { anos, dentista, tem } 3 \\
\text { filhos, casado há } 5 \text { anos com Kátia tem vários } \\
\text { amigos e alguns inimigos }\end{array}$ & $\begin{array}{l}\text { Maria Eduarda, } 26 \text { anos, advogada, noiva há } 4 \\
\text { anos de Ronaldo já ganhou vários casos na } \\
\text { justiça e perdeu alguns }\end{array}$ \\
\hline 2 & $\begin{array}{l}\text { Eduardo, } 28 \text { anos, engenheiro mecânico, tem } \\
2 \text { filhos, casado há } 5 \text { anos com Patrícia } \boldsymbol{e} \\
\text { amante de Juliana há } 3 \text { anos }\end{array}$ & $\begin{array}{l}\text { Ana Paula, } 23 \text { anos, corretora de imóveis, } \\
\text { noiva há } 3 \text { anos de Henrique assediou } 4 \\
\text { homens numa festa do trabalho }\end{array}$ \\
\hline 3 & $\begin{array}{l}\text { Marcelo, } 23 \text { anos, corretor de imóveis, noivo } \\
\text { há } 3 \text { anos de Ana Luísa assediou } 4 \text { mulheres } \\
\text { numa festa do trabalho }\end{array}$ & $\begin{array}{l}\text { Aline, } 25 \text { anos, bióloga, namora há } 2 \text { anos } \\
\text { com Caio e paquerou (ficou) com } 5 \text { rapazes } \\
\text { durante o seu relacionamento }\end{array}$ \\
\hline 4 & $\begin{array}{l}\text { Tiago, } 22 \text { anos, estudante de medicina, } \\
\text { namora há } 1 \text { ano com Paula tem dificuldade } \\
\text { em algumas matérias do curso. }\end{array}$ & $\begin{array}{l}\text { Poliana, } 22 \text { anos, estudante de medicina, } \\
\text { namora há } 1 \text { ano com Alan tem dificuldade } \\
\text { em algumas matérias do curso }\end{array}$ \\
\hline 5 & $\begin{array}{l}\text { Vitor, } 25 \text { anos, biólogo, namora há } 2 \text { anos } \\
\text { com Lara e paquerou (ficou) com } 5 \text { garotas } \\
\text { durante o seu relacionamento }\end{array}$ & $\begin{array}{l}\text { Renata, } 28 \text { anos, engenheira mecânica, tem } 2 \\
\text { fillhos, casada há } 5 \text { anos com Leonardo } \boldsymbol{e} \\
\text { amante de Roberto há } 3 \text { anos }\end{array}$ \\
\hline 6 & $\begin{array}{l}\text { Antônio Carlos, } 26 \text { anos, advogado, noivo há } \\
4 \text { anos de Mariana já ganhou vários casos na } \\
\text { justiça e perdeu alguns }\end{array}$ & $\begin{array}{l}\text { Priscila, } 29 \text { anos, dentista, tem } 3 \text { filhos, } \\
\text { casada há } 5 \text { anos com Luís Carlos tem vários } \\
\text { amigos e alguns inimigos }\end{array}$ \\
\hline
\end{tabular}

* Em destaque, para cada uma das descrições, as histórias de infidelidade acrescentada às informações pessoais apresentadas para o grupo IPH.

\section{Procedimento}

Na primeira fase, cada participante preencheu um formulário avaliando a atratividade física de cada uma das pessoas nas vinte fotografias apresentadas. Os participantes de sexo masculino avaliaram as fotografias de mulheres, enquanto as participantes de sexo feminino avaliaram as fotografias de homens. Os participantes controlaram à vontade o tempo de exibição de cada fotografia, avançando manualmente cada "slide".

Calcularam-se, para cada fotografia, a média e o desvio padrão das notas recebidas. As fotografias selecionadas para a segunda fase do estudo foram aquelas que receberam uma avaliação média entre quatro e sete e que tiveram os menores desvios-padrão, resultando na seleção de seis fotografias de homens e seis fotografias de mulheres.

$\mathrm{Na}$ segunda fase da pesquisa, os participantes foram divididos em dois grupos: IP (informações pessoais) e IPH (Informações pessoais e história). Ao grupo IP (cinquenta e quatro homens e cinquenta e quatro mulheres) foram apresentadas as seis fotografias (homens viram as fotos de mulheres e mulheres viram as fotos de homens) acompanhadas apenas das informações pessoais. Ao grupo IPH (cinquenta e um homens e cinquenta mulheres) foram apresentadas as mesmas seis fotografias acompanhadas das informações pessoais e das histórias. As fotografias com histórias neutras e com histórias de infidelidade foram apresentadas sempre na mesma ordem para todos os participantes (fotos 1, 4 e 6 acompanhadas pela história neutra e fotos 2,3 e 5 acompanhadas pela história de infidelidade). Requisitava-se que os participantes julgassem a atratividade física das pessoas fotografadas atribuindo uma nota de zero a dez.

\section{Análises}

As notas atribuídas às fotografias por homens e mulheres dos dois grupos de participantes, IP e IPH, foram comparadas intra-sexo usando o teste de Mann-Whitney para duas amostras independentes.

\section{Resultados}

As notas médias atribuídas à atratividade das pessoas fotografadas variaram de 3,26 a 6,0 como esperado de acordo com a seleção, na primeira fase do estudo, de fotografias julgadas como possuindo atratividade média.

Comparamos as notas de atratividade dadas às pessoas fotografadas quando as fotografias eram acompanhadas apenas pelas informações pessoais (IP) à nota dada às pessoas fotografadas quando as fotografias eram acompanhadas pelas informações pessoais e pela história (IPH).

Entre os participantes do sexo masculino não foram encontradas diferenças significativas entre os grupos IP e IPH para nenhuma das fotografias apresentadas, independentemente 
das informações para o grupo IPH conterem histórias sobre infidelidade ou histórias neutras (Figura 1). No entanto, entre as mulheres houve diferença significativa nas notas atribuídas a duas das seis fotografias apresentadas (fotografia 2: $z=$ $-3,729 ; p<0,001$; fotografia $3: z=-3,538 ; p<0,001$; Figura
1), sendo que estas foram apresentadas para o grupo IPE acompanhadas das histórias sobre infidelidade. Apenas uma das fotografias masculina acompanhada por história de infidelidade não apresentou diferença entre as mulheres dos dois grupos (fotografia 5).

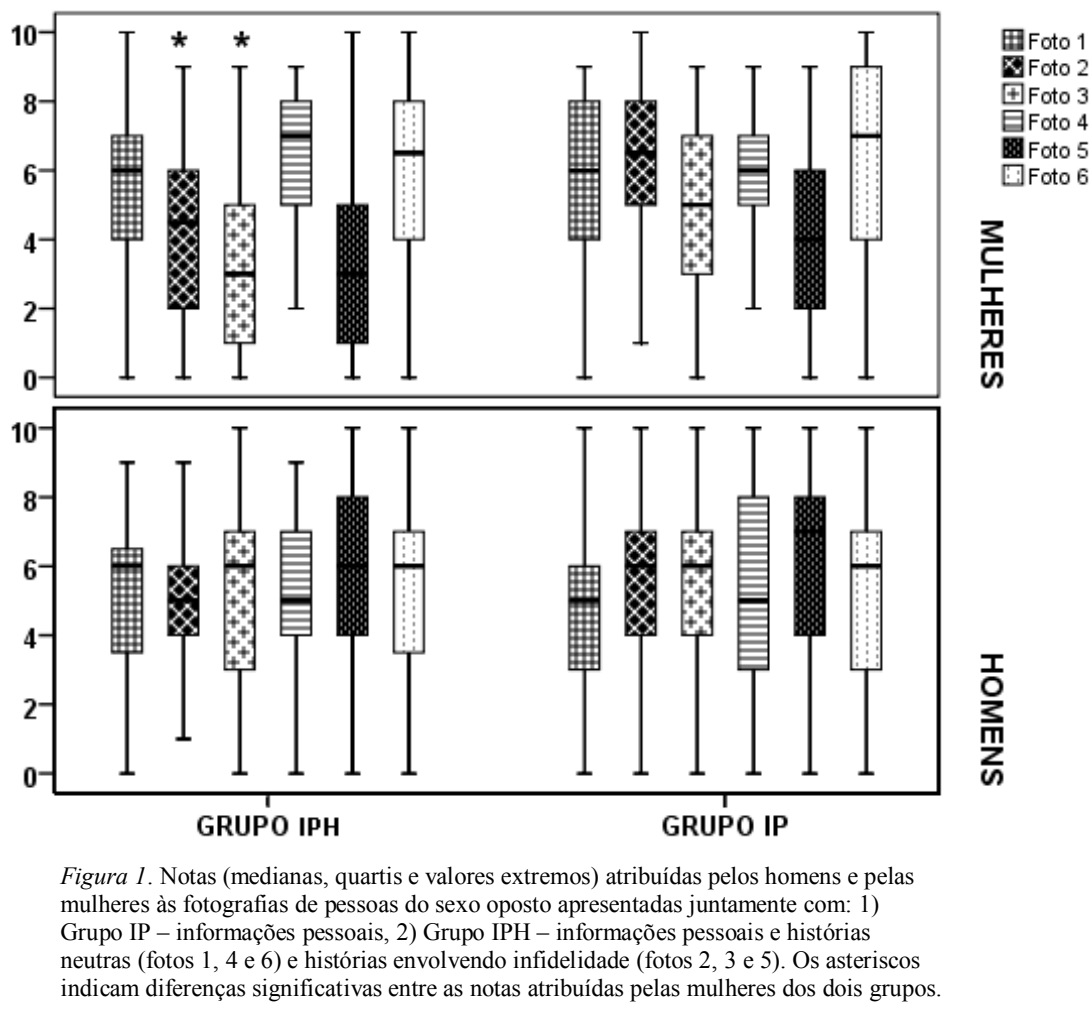

\section{Discussão}

Nossos resultados indicam que a avaliação da atratividade foi influenciada pelo fornecimento de informações relacionadas ao comportamento de infidelidade apenas quando as mulheres julgaram a atratividade de homens.

É interessante notar que uma das fotografias (foto 5) apresentada às mulheres acompanhada por história de infidelidade não apresentou diferença significativa entre os grupos de mulheres, embora seja percebida uma tendência para a redução da avaliação de atratividade. É talvez digno de nota que no grupo controle - que não tinha acesso à história de infidelidade - essa fotografia foi avaliada com a menor média. Outro fator que deve ser mencionado é o fato de que a história associada a essa foto indicava que o personagem namorava há dois anos e que "paquerou (ficou) com cinco garotas durante o relacionamento", enquanto as outras duas histórias de infidelidade envolviam um homem que era casado e tinha uma amante e outro que era noivo e havia assediado quatro mulheres em uma festa do trabalho. Uma possível explicação para a ausência de diferença significativa para esta fotografia inclui a possibilidade de que o relacionamento "namoro" seja menos importante, em termos da expectativa de fidelidade, do que os relacionamentos "casamento" ou "noivado", entre as mulheres.
Buss e Schimidt (1993) mostraram que homens e mulheres apresentam expectativas diferentes quanto ao comprometimento em relacionamentos de curto e longo prazo.

A perspectiva da Psicologia Evolucionista, ao apontar fatores relacionados à seleção natural como influências sobre a motivação e as emoções humanas, pode sugerir explicações para essa diferença entre homens e mulheres. Buss e Schmitt (1993), em sua Teoria de Estratégias Sexuais, apontam que existem problemas adaptativos diferentes a se resolverem, tanto quando se comparam machos e fêmeas quanto ao se compararem relacionamentos de curta e de longa duração. As estratégias sexuais desenvolvidas historicamente, portanto, seriam diferentes para cada sexo, e em cada situação. Segundo Buss e Schmitt (1993), em situações de relacionamento de curta duração, os homens precisariam resolver problemas ligados ao número de parceiras, à fertilidade, à identificação de acessibilidade sexual das candidatas e à minimização dos custos e riscos. Já às mulheres se apresentam problemas como a obtenção de recursos, a qualidade genética do parceiro e a possibilidade de transformar o relacionamento em um de longo prazo. Nossos resultados são compatíveis com essas hipóteses, mostrando uma maior valorização pelas mulheres de fatores que remetam ao prolongamento do relacionamento e à manutenção dos recursos materiais. 
Outros fatores também devem ser lembrados, em especial fatores ligados às convenções e às pressões sócio-culturais, que têm sido mais permissivas quanto à infidelidade masculina do que em relação à feminina. Levesque, Vichesky, Simmons, Wicke e Lipe (2007) referem-se à maior aceitação social de comportamentos sexuais dos homens como um duplo padrão sexual, apontando para várias explanações possíveis para esse duplo padrão. Em seu estudo, no entanto, foram as mulheres que atribuíram maior quantidade de comentários negativos aos homens com histórias de promiscuidade do que os homens, em relação às mulheres supostamente promíscuas. Esse resultado parece indicar um efeito semelhante ao encontrado por nós: a promiscuidade ou infidelidade parece afetar o julgamento das mulheres, mas não o dos homens. A promiscuidade, no estudo citado, não teve influência significativa na avaliação da atratividade física, provavelmente porque foram utilizadas imagens dicotômicas (de alta ou de baixa atratividade), contrastando com nosso estudo, que se baseou em imagens de atratividade mediana. Levesque et al. (2007) levantam a hipótese de que o estereótipo de atratividade física tenha suplantado qualquer efeito de diferença entre os sexos ou de promiscuidade, para explicar seus resultados.

Souza Campos, Otta e Siqueira (2002) estudaram as diferenças sexuais em estratégias de seleção de parceiros através de anúncios pessoais nos classificados de um jornal de grande circulação no Brasil, encontrando uma maior resposta aos anúncios de mulheres quando são anunciadas características físicas e aos anúncios de homens quando são anunciadas características relacionadas ao status socioeconômico. Ramos e Pasquali (1993) mostraram, aplicando sua própria "escala de atração intersexual", que as pessoas mais novas dão maior relevância ao aspecto estético do que as mais velhas. Por outro lado, o estudo não mostrou diferenças significativas entre homens e mulheres, quanto à valorização do aspecto estético. Féres-Carneiro (1997) demonstraram que tanto homens quanto mulheres heterossexuais valorizam a fidelidade, o companheirismo, a integridade, o carinho e a paixão. No entanto, a juventude e a atratividade física foram significativamente mais importantes para os homens, enquanto a capacidade econômica e a competência profissional foram significativamente mais valorizadas pelas mulheres. A importância da atratividade física se manteve inclusive para os homens homossexuais, que, no entanto, também valorizaram significativamente mais que os heterossexuais o atributo competência profissional. Por outro lado, as mulheres homossexuais atribuíram menor valor para esse atributo que as mulheres heterossexuais. De uma forma geral, esses estudos apontam para uma tendência masculina para uma maior valorização das características físicas isoladas, enquanto as mulheres tendem a valorizar características não-físicas.

Apesar de utilizarmos fotografias de pessoas desconhecidas, em vez de avaliarmos a importância dos fatores não-físicos sobre a avaliação de atratividade de pessoas conhecidas, como fizeram Kniffin e Wilson (2004), nossos resultados se assemelham bastante aos obtidos por esses autores. Nossos resultados mostram de forma evidente a diferença entre homens e mulheres, em relação à importância do fator infidelidade ao avaliarem a atratividade de pessoas do outro sexo.

Estas diferenças podem ser entendidas a partir da consideração dos custos reprodutivos diferenciais para os sexos. Os custos com o cuidado parental recaem principalmente sobre as mulheres, dada a gestação interna e a amamentação (Tokumaru, 2009). Como proposto por Trivers (1972) em sua teoria do Investimento Parental, o sexo que investe menos em cuidado parental tende a competir pelo sexo que investe mais, enquanto este tende a ser mais seletivo. No caso humano, as mulheres, com altos custos reprodutivos em relação aos homens, tendem a ser mais seletivas e podem ter sido selecionadas de forma a atentar para as características não físicas indicadoras de disponibilidade de investimento, enquanto os homens foram selecionados de forma a atentar para características que indicam capacidade reprodutiva, como a aparência física e a juventude. Há inúmeras demonstrações de que estas diferenças estejam presentes quando homens e mulheres atribuem valor diferencial a estas características em parceiros românticos (Buss, 1989; Buss et al., 2001; Gangestad, Haselton, \& Buss 2006; Shackelford, Schmitt, Buss, 2005). Neste contexto, o julgamento de atratividade do sexo oposto de homens e mulheres pode representar adaptações diferentes. Os homens tenderiam a ser mais sensíveis, a princípio, às características físicas e contextuais (como a presença de acompanhantes do sexo oposto, Hill \& Buss, 2008) enquanto as mulheres julgariam a atratividade baseando-se em todas as informações físicas, pessoais e contextuais disponíveis. A ênfase na proposta de que homens e mulheres apresentem sensibilidade diferencial às características físicas e não físicas refere-se ao julgamento feito de forma imediata da atratividade de um indivíduo do sexo oposto. Como indicado por Kniffin e Wilson (2004), o julgamento da atratividade tanto de homens como de mulheres é grandemente afetado pela convivência, ainda que os resultados destes autores tenham demonstrado maior efeito no julgamento feminino.

No entanto, apesar da ausência de diferenças entre os homens com e sem acesso as informações sobre a infidelidade feminina neste trabalho, outros autores indicam que a fidelidade é valorizada por homens e mulheres, principalmente em relacionamentos de longo prazo (Buss, 1989; Buss \& Barnes, 1986; Easton et al., 2007; Miller, 2007; Minervini \& McAndrew, 2006; Rowatt et al., 2001; Shackelford \& Buss, 1997). Podemos hipotetizar que o julgamento dos homens sobre a atratividade de mulheres também seria afetado se fossem instruídos a julgar a atratividade das mulheres considerando-as como candidatas para relacionamentos de longo prazo. Outros estudos devem considerar esta possibilidade ao buscarem compreender as diferenças no julgamento de atratividade de homens e mulheres e do efeito de informações não físicas sobre este julgamento.

Embora concordemos com Kniffin e Wilson (2004) em seus argumentos criticando estudos que se utilizem apenas de fotografias de pessoas desconhecidas, talvez esse tipo de estudo seja mais adequado para se isolarem características não-físicas específicas, como foi o caso da infidelidade, no presente trabalho. Novas pesquisas, com amostras maiores e mais diversificadas, são requeridas para que possamos ampliar a significância de nossos resultados. 


\section{Referências}

Bronstad, P. M., \& Russell, R. (2007). Beauty is in the 'we' of the beholder: greater agreement on facial attractiveness among close relations. Perception, $36,1674-1681$.

Buss, D. M. (1989). Sex differences in human mate preferences: evolutionary hypotheses tested in 37 cultures. Behavioral and Brain Science, 12(1), 1-49.

Buss, D. M., \& Barnes, M. (1986). Preferences in human mate selection. Journal of Personality and Social Psychology, 50(3), 559-570.

Buss, D. M., \& Schmitt, D. P. (1993). Sexual Strategies Theory: an evolutionary perspective on human mating. Psychological Review, 100(2), 204-232.

Buss, D. M., Shackelford, T., Kirkpatrick, L., \& Larsen, R. (2001). A half century of mate preferences: the cultural evolution of values. Journal of Marriage Family, 63, 491-503.

Cornwell, R. E., Boothroyd, L., Burt, D. M., Feinberg, D. R., Jones, B. C., Little, A. C., ... Perret, D. I. (2004). Concordant preferences for opposite-sex signals? Human pheromones and facial characteristics. Proceedings of Royal Society of London B Biology, 271, 635-640.

Dion, K., Berscheid, E., \& Walster, E. (1972). What is Beautiful is good. Journal of Personality and Social Psychology, 24(3), 285-290.

Easton, J., Schipper, L., \& Shackelford, T. (2007). Morbid jealousy from an evolutionary psychological perspective. Evolution Human Behavior, 28(6), 399-402.

Elovitz, G. P., \& Salvia, J. (1982). Attractiveness as a biasing factor in the judgments of school psychologists. Journal of School Psychology, 20, 339-345.

Fan, J., Dai, W., Qian, X., Chau, K. P., \& Liu, Q. (2007). Effects of shape parameters on the attractiveness of a female body. Perceptual Motor Skill, 105(1), 117-132.

Féres-Carneiro, T. (1997). A escolha amorosa e interação conjugal na heterossexualidade e na homossexualidade. Psicologia: Reflexão Crítica, 10(2), 351-368.

Fink, B., Neave, N., \& Seydel, H. (2007). Male facial appearance signals physical strength to women. American Journal of Human Biology, 19(1), 82-87.

Gangestad, S., Haselton, M., \& Buss, D. M. (2006). Evolutionary foundations of cultural variation: evoked culture and mate preferences. Psychological Inquiry, 17(2), 75-95.

Gladue, B. A., \& Delaney, H. J. (1990). Gender differences in perception of attractiveness of men and women in bars. Personality and Social Psychology Bulletin, 16(2), 378-391.

Gross, A. E., \& Crofton, C. (1977). What is good is beautiful. Sociometry, 40(1), 85-90.

Hill, S. E., \& Buss, D. M. (2008). The mere presence of opposite-sex others on judgments of sexual and romantic desirability: opposite effects for men and women. Personality and Social Psychology Bulletin, 34(5), 635-647.

Hönekopp, J. (2006). Once more: is beauty in the eye of the beholder? Relative contributions of private and shared taste to judgments of facial attractiveness. Journal of Experimental Psychology [Human Perception], 32(2), 199-209.

Hönn, M., \& Göz, G. (2007). The ideal of facial beauty: a review. Journal of Orofacial Orthopedics, 68(1), 6-16.

Houle, D., \& Kondrashov, A. S. (2002). Coevolution of costly mate choice and condition-dependent display of good genes. Proceedings of Royal Society of London B Biology, 269, 97-104.

Jensen-Campbell, L. A., Graziano, W. G., \& West, S. G. (1995). Dominance, prosocial orientation, and female preferences: do nice guys really finish last? Journal of Personality and Social Psychology, 68(3), 427-440.

Jones, B. C., DeBruine, L. M., Perrett, D. I., Little, A. C., Feinberg, D. R., \& Law Smith, M. J. (2008). Effects of menstrual cycle phase on face preferences. Archives of Sexual Behavavior, 37, 78-84.
Kniffin, K. M., \& Wilson, D. S. (2004). The effect of nonphysical traits on the perception of physical attractiveness. Three naturalistic studies. Evolution and Human Behavior, 25, 88-101.

Lee-Manoel, C. L., Morais, M. L. S., Bussab V. S. R., \& Otta, E. (2002). Quem é bom (e eu gosto) é bonito: efeitos da familiaridade na percepção de atratividade física em pré-escolares. Psicologia: Reflexão e Crítica, 15(2), 271-282.

Levesque, M., Vichesky, D., Simmons, M., Wicke, K., \& Lipe, A. (2007). Physical attractiveness and sex in judgments about perceived sexually promiscuous others. Psychological Reports, 100, 1107-1112.

Lippa, R. A. (2007). The preferred traits of mates in a cross-national study of heterosexual and homosexual men and women: an examination of biological and cultural influences. Archives of Sexual Behavior, 36, 193-208.

Little, A. C., Apicella, C. L., \& Marlowe, F. W. (2007). Preferences for symmetry in human faces in two cultures: data from the UK and the Hazda, an isolated group of hunter-gatherers. Proceedings of Royal Society of London B Biology, 274(1629), 3113-3117.

Miller, G. F. (2007). Sexual selection for moral virtues. Quarterly Review of Biology, 82(2), 97-125.

Minervini, B. P., \& McAndrew, F. T. (2006). The Mating Strategies and Mate Preferences of Mail Order Brides. Cross-Cultural Research, 40(2), 111-129.

Omote, S. (1991). Efeitos da atratividade física facial de crianças sobre a percepção de outras qualidades delas. Psicologia: Teoria e Pesquisa, 7(3), 295-302.

Omote, S. (1994). Fidedignidade na percepção da atratividade física facial. Psicologia: Teoria e Pesquisa, 10(2), 143-157.

Perrett, D. I., Lee, K. J., Penton-Voak, I. S., Rowland, D., Yoshikawa, S., Burt, D. M., ... Akamatsu, S. (1998) Effects of sexual dimorphism on facial attractiveness. Nature, 394(27), 884-887.

Penton-Voak, I. S., Jones, B. C., Little, A. C., Baker, S., Tidderman, B., Burt, D. M., \& Perret, D. I. (2001). Symmetry, sexual dimorphism in facial proportions and male facial attractiveness. Proceedings of Royal Society of London B Biology, 268, 1617-1623.

Ramos, A. L. M., \& Pasquali, L. (1993). Atração intersexual por aparência física. Psicologia: Teoria e Pesquisa, 9(1), 193-205.

Rhodes, G. (2006). The evolutionary psychology of facial beauty. Annual Review of Psychology, 57, 199-226.

Roney, J. R., Hanson, K. N., Durante, K. M., \& Maestripieri, D. (2006). Reading men's faces: women's mate attractiveness judgments track men's testosterone and interest in infants. Proceedings of Royal Society of London B Biology, 273, 2169-2175.

Ross, M. B., \& Salvia, J. (1975). Attractiveness as a biasing factor in teacher judgments. American Journal of Mental Deficiency, 80, 96-98.

Rowatt, W., Delue, S., Strickhouser, L., \& Gonzalez, T. (2001). The limited influence of self-monitoring on romantic partner preferences. Personality and Individual Differences, 31(6), 943-954.

Shackelford, T., \& Buss, D. M. (1997). Cues to infidelity. Personality and Social Psychology Bulletin, 23(4), 1034-1045.

Shackelford, T., Schmitt, D., \& Buss, D. M. (2005). Universal dimensions of human mate preferences. Personality and Individual Differences, 39(2), 447-458.

Schützwohl, A. (2006). Judging female figures: a new methodological approach to male attractiveness judgments of female waist-to-hip ratio. Biological Psychology, 71(2), 223-229.

Sousa Campos, L., Otta, E., \& Siqueira, J. O. (2002). Sex differences in mate selection strategies: content analyses and responses to personal advertisements in Brazil. Evolution and Human Behavior, 23, 395-406.

Swami, V., \& Tovée, M. J. (2005). Female physical attractiveness in Britain and Malaysia: a cross-cultural study. Body Image, 2(2), 115-128.

Thorndike, E. L. (1920). A Constant Error in Psychological Rating. Journal of Applied Psychology, 4, 25-29. 
Tokumaru, R. S. (2009). Investimento parental e maus tratos de crianças. In E. Otta \& M. E. Yamamoto (Orgs.), Psicologia Evolucionista (pp. 96-102). Rio de Janeiro: Guanabara Koogan.
Trivers, R. (1972). Parental investment and sexual selection. In B. Campbel (Org.), Sexual selection and the descent of man 1871-1971 (pp. 136-179). Chicago: Aldine Publishing Company.

Rosana Suemi Tokumaru, doutora em Psicologia Experimental pela Universidade de São Paulo, é professora adjunta do Departamento de Psicologia Social e do Desenvolvimento da Universidade Federal do Espírito Santo. Endereço para correspondência: Departamento de Psicologia Social e do Desenvolvimento. Universidade Federal do Espírito Santo. Av. Fernando Ferrari, 514, Goiabeiras, Vitória, ES, Brasil CEP 29075-910. Telefax: +55 27 3335-2505 / 2501. E-mail: suemitokumaru@gmail.com

Sérgio Werner Baumel, especialista em Sexologia Clínica pela Faculdade Salesiana de Vitória, é médico neurologista e intensivista (autônomo).

Fabiane Cruz Gama Aires é graduanda em Psicologia na Universidade Federal do Espírito Santo. Daniela Palaoro Viana é graduanda em Psicologia na Universidade Federal do Espírito Santo. Laís de Almeida Ambrósio é graduanda em Psicologia na Universidade Federal do Espírito Santo. Yara Nascimento de Aguiar é graduanda em Psicologia na Universidade Federal do Espírito Santo. Rojane Neves Monteiro é graduanda em Psicologia na Universidade Federal do Espírito Santo. 